\title{
Por uma poética cartesiana: gráficos 3D nas criações digitais de André Vallias
}

\author{
On a Cartesian Poetics: 3D Plots in André Vallias's Digital Creations
}

Por una poética cartesiana: gráficos 3D en las creaciones digitales de André Vallias

Vinícius Carvalho Pereira*

\begin{abstract}
Resumo
O laureado artista visual e poeta André Vallias, internacionalmente conhecido por suas criações na esfera da literatura eletrônica e das artes digitais, frequentemente lança mão das potencialidades do ciberespaço para a constituição multissemiótica de suas obras. Além de elementos mais comuns no campo dos diálogos interartes, tais como imagens, cores, volumes, movimento e sons, Vallias costuma empregar em suas criações um tipo de signo insólito em obras artísticas: gráficos matemáticos 3D. Trata-se de representações visuais tridimensionais (mas expressas em superfícies bidimensionais, como telas de computador e celular) de funções algébricas construídas com o software AutoCad - geralmente utilizado em projetos de áreas como a Engenharia e a Arquitetura -, às quais Vallias agrega valor artístico por meio da combinação com elementos mais tradicionais do gênero lírico, como a versificação e o ritmo. Em suas obras, tais gráficos desencadeiam um ou mais efeitos estéticos, como a representação icônica de formas geométricas do mundo referencial, a desconstrução de redutoras antinomias como subjetividade/objetividade (e, por conseguinte, pensamento poético/pensamento matemático), ou a alusão simbólica a elementos intangíveis de textos líricos, sobretudo fenômenos dos estratos fonológico e visual. Nesse contexto, o presente artigo analisa três obras de André Vallias - Nous n'avons pas compris Descartes (1997), De verso (s.d.) e Oratorio (2004) - a fim de mapear o rendimento estético do uso de gráficos matemáticos 3D como recursos artísticos que desnaturalizam nossa percepção acerca do literário e seu atravessamento por sistemas semióticos inusitados.
\end{abstract}

Palavras-chave: André Vallias, gráficos 3D, poesia digital, metapoesia.

\section{Abstract}

The award-winning Brazilian visual artist and poet André Vallias, internationally renowned for his creations in electronic literature and digital arts, frequently uses cyberspace potentialities to engender his multisemiotic works. Besides the more common elements within interartistic dialogues, such as images, colors, volumes, movement and sounds, Vallias often adds to his creations a kind of sign that is unusual in works of art: 3D plots. These are tridimensional visual representations (but expressed on bidimensional surfaces, such as computer screens and smartphone screens) of algebraic functions built with AutoCad software - often used in Engineering and Architecture projects -, to which Vallias adds artistic value by combining them with traditional elements of the lyrical genre, such as versification and rhythm. In his works, these plots trigger one or more aesthetic effects, such as the iconic representation of geometric

\section{Resumen}

El galardonado artista visual y poeta André Vallias, internacionalmente conocido por sus creaciones en la esfera de la literatura electrónica y de las artes digitales, a menudo emplea las potencialidades del ciberespacio para la constitución multisemiótica de sus obras. Además de elementos más comunes en el campo de los diálogos entre artes, tales como imágenes, colores, volúmenes, movimiento $\mathrm{y}$ sonidos, Vallias suele emplear en sus creaciones un tipo de signo insólito en obras artísticas: gráficos matemáticos 3D. Estos son representaciones visuales tridimensionales (pero expresadas en superficies bidimensionales, como pantallas de ordenadores y celulares) de funciones algebraicas construidas con el software AutoCad - generalmente utilizado en proyectos de áreas como la Ingeniería y la Arquitectura -, a las cuales Vallias agrega valor artístico por la combinación con elementos más tradicionales del género lírico, como la versificación y el ritmo. En sus obras, los gráficos desencadenan

\footnotetext{
Universidade Federal de Mato Grosso (UFMT), Cuiabá, MT, Brasil. (Dorcid.org/0000-0003-1844-8084. E-mail: viniciuscarpe@gmail.com
} 
shapes from the referential world; the deconstruction of reductionist antinomies, like subjectivity/objectivity (hence, poetic thought/mathematical thought); or the symbolic allusion to intangible elements of lyrical texts, especially phenomena from the phonological and the visual strata. In this context, we herein analyze three works by André Vallias - Nous n'avons pas compris Descartes (1997), De verso (s.d.) and Oratorio (2004) - in order to map out the aesthetical outcomes of his use of mathematical $3 \mathrm{D}$ plots as artistic resources that denaturalize our perception of the literary and its connections with unexpected semiotic systems.

Keywords: André Vallias, 3D plots, digital poetry, metapoetry. uno o más efectos estéticos, como la representación icónica de formas geométricas del mundo referencial, la deconstrucción de antinomias reductoras como subjetividad/objetividad $(\mathrm{y}$, por tanto, pensamiento poético/pensamiento matemático), o la alusión simbólica a elementos intangibles de textos líricos, sobre todo fenómenos de los estratos fonológico y visual. En este contexto, este artículo analiza tres obras de André Vallias Nous n'avons pas compris Descartes (1997), De verso (s.d.) y Oratorio (2004) - a fin de mapear el producto estético del uso de gráficos matemáticos 3D como recursos artísticos que desnaturalizan nuestra percepción de lo literario y su atravesamiento por sistemas semióticos inusitados.

Palabras-clave: André Vallias, gráficos 3D, poesía digital, metapoesía.

\section{André Vallias e a poesia digital}

Mais conhecido nas áreas de design e comunicação social do que nos círculos acadêmicos das letras no Brasil, André Vallias é poeta digital de renome na comunidade internacional de pesquisadores de literatura eletrônica. ${ }^{1}$ Seu trabalho com textos hipermídia para recepção em microcomputadores ou instalações em galerias é frequentemente citado em compilações/antologias especializadas na área, como a Brazilian Digital Art and Poetry on the Web (Antonio, s.d.); em repositórios digitais, como a Enciclopédia Itaú Cultural (André, 2018), ou a base de dados da Electronic Literature as a Model of Creativity and Innovation in Practice (André, 2019); e em publicações acadêmicas de peso, como a obra Prehistoric digital poetry: an archaeology of forms, 1959-1995, de Christopher Thompson Funkhouser (2007). Sobre esta última, referência bibliográfica quase obrigatória acerca da história das obras de literatura eletrônica desenvolvidas antes do advento da internet, cumpre ressaltar que a capa da edição de 2007 é ilustrada por uma criação de Vallias - De verso, analisada mais adiante neste artigo -, tamanho é o reconhecimento do poeta brasileiro entre os especialistas.

Também o título do livro de Funkhouser é relevante para entendermos o contexto em que se insere a produção de Vallias: ao tomar seu objeto de estudo como parte da "pré-história" da poesia digital, o pesquisador demarca que as obras de que trata seu livro foram compostas antes da constituição da poesia digital como um campo de pesquisa e atuação (Funkhouser, 2007) e antes da rede mundial de computadores, que mudou radicalmente as formas de expressão e interação mediadas por tecnologias. Assim, tendo iniciado seus projetos ciberpoéticos na segunda metade do século XX, os artistas digitais da época, como Vallias, trabalhavam ainda majoritariamente isolados, isto é, com poucos recursos técnicos que permitissem a circulação e a recepção de suas obras. Antes da internet, a distribuição de tais textos estava restrita a disquetes e CD-ROMs trocados por correio ou em encontros presenciais. Muitas dessas obras são hoje inacessíveis, seja porque não sobreviveram ao desgaste físico do tempo e às condições

\footnotetext{
${ }^{1}$ Não há, no meio acadêmico, consenso quanto à nomenclatura utilizada para se referir a produções dessa natureza. A maioria dos autores, como Hayles (2009), Santaella (2012) e Santos (2003), utilizam de forma indistinta termos como "literatura eletrônica", "literatura cibernética/ciberliteratura" e "literatura digital", opção também adotada neste artigo. Ainda que se reconheça que cada um desses adjetivos atrelados ao substantivo "literatura" denota a especificidade do campo por uma associação particular (respectivamente, ao eletrônico, em oposição ao elétrico; ao cibernético, por referência à comunicação entre máquinas; e ao digital, em oposição ao analógico), o conjunto de obras recobertas pelos três termos é praticamente o mesmo, o que justifica seu uso intercambiável neste contexto.
} 
inadequadas de armazenamento, seja porque sobraram poucos dispositivos ainda capazes de ler seus dados, haja vista a rápida obsolescência das tecnologias digitais.

No caso de André Vallias, porém, esse problema é minorado graças ao esforço do artista para a transposição de seus trabalhos para a web e para a manutenção de seu site (http://www.andrevallias.com/), onde se podem encontrar, ainda hoje, muitos de seus poemas agora, renderizados para a web. Entre estes, destacam-se os que, evidenciando sua expertise em design e hipermídia, combinam elementos verbais e não verbais para experimentos metapoéticos.

No presente artigo, tomam-se como objetos de análise três criações digitais de Vallias - Nous n'avons pas compris Descartes (1997), De verso (2003) e Oratorio (2004) -, a fim de indagar a dimensão metapoética que, nessas obras, é expressa por um elemento inusitado em poemas (quer impressos, quer eletrônicos): o uso de gráficos em 3D. Para tanto, procede-se nas próximas seções a um close reading dos poemas, considerando tanto sua materialidade verbal quanto a desconcertante presença dos gráficos tridimensionais de eixos ortogonais cartesianos, de modo a ressaltar como tais elementos evidenciam, na produção de Vallias, uma concepção matemática do lírico.

\section{Ciber-ars poetica: gráficos de uma função}

$\mathrm{Na}$ contramão do senso comum de que Literatura e Matemática seriam áreas do conhecimento antípodas - reproduzindo um questionável binarismo metafísico entre subjetividade e objetividade, ou imaginação e cálculo -, cruzamentos entre ambos os campos proliferaram entre artistas de vanguarda do século $X X$, muitos dos quais vieram a influenciar, posteriormente, os primeiros projetos de literatura digital.

Na França da década de 60, por exemplo, em que os ambientes intelectuais apresentavam grande entusiasmo diante de uma proposta científica de descrição e análise da língua e da literatura - o Estruturalismo -, ao mesmo tempo em que outros pensadores apregoavam o Existencialismo e o Surrealismo como respostas à depressão pós-guerra e à crise do sentido, surgiu o grupo artístico OuLiPo (Ouvroir de Littérature Potentielle), preconizando um novo olhar sobre a linguagem e o objeto literário.

Em contraponto à literatura aleatória ou inconsciente do Surrealismo, propunha-se no programa oulipiano uma perspectiva formalista da linguagem e da literatura, "[...] no que tange à elementar e científica ordem das estruturas da linguagem" (Oulipo, 1973), as quais poderiam ser descritas e ampliadas por modelos matemáticos redigidos como contraintes. Termo francês de difícil tradução, mas com sentido próximo ao de "travas", "constrições" ou "restrições", as contraintes se dariam na forma geral de desafios ou axiomas, como escrever um texto sem determinada letra, com um inovador padrão métrico, reiterando certo trocadilho fonético etc., $\mathrm{o}$ que valoriza o caráter material da literatura e a imanência do texto como jogo de significantes, análogo à manipulação de variáveis em uma equação.

Redigidas segundo tal diapasão, obras como as de Raymond Queneau, George Perec, Jacques Roubaud, entre outros escritores oulipianos, denotam uma empreitada matemáticoliterária que, alguns anos mais tarde, começou a ser realizada em meio digital em diferentes partes do mundo, inclusive no Brasil. Em nosso país, os experimentos poéticos com linguagens matemáticas e de programação também foram, desde o início, fortemente influenciados pela poesia concreta e sua sistemática pesquisa estética quanto às potencialidades do poema como objeto visual. É, pois, nesse contexto que deve ser entendida a produção de André Vallias, o qual combina múltiplas semioses na elaboração de seus poemas eletrônicos.

Como ponto de intercessão entre as linguagens verbal, matemática e visual, figura reiteradamente nas obras de Vallias o uso de gráficos tridimensionais representativos de funções algébricas como enunciados metapoéticos. Estes, porém, em lugar de serem formulados 
segundo procedimentos retóricos caros à tradição lírica ocidental, são graficamente compostos como coordenadas em eixos ortogonais ${ }^{2}$ no software AutoCad, utilizado para desenho técnico.

O conceito matemático de função pode ser definido, em linhas gerais, como designando uma relação entre dois conjuntos. Tal relação pode ser expressa, entre outras formas, em uma linguagem algébrica, como no enunciado $\mathrm{f}(\mathrm{x})=\mathrm{y}$, ou, de maneira mais visual, em um gráfico de eixos ortogonais. No dia a dia, podemos ver gráficos dessa natureza, sobretudo os bidimensionais, expressos no plano cartesiano, relacionando valores dos eixos das abscissas e das ordenadas. Nas criações de Vallias, por sua vez, abundam gráficos tridimensionais, muitos dos quais representam formas geométricas complexas e ricas de movimento e elegância, como as do ciberpoema Nous n'avons pas compris Descartes, de que se reproduz, a seguir, uma captura de tela (Figura 1).

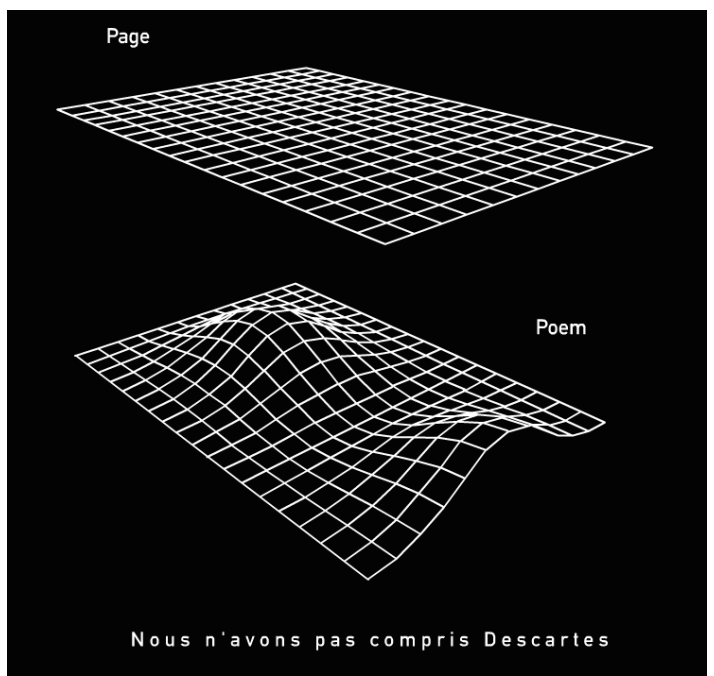

Figura 1 - Captura de tela de Nous n'avons pas compris Descartes

Fonte: Vallias (1997).

Em linhas e letras brancas contra um fundo negro, o ciberpoema vai se formando gradualmente na tela: primeiro, aparecem, a um só tempo, a palavra "Page" e o plano euclidiano próximo a ela; em seguida, vai se desenhando, de cima para baixo e da esquerda para a direita, o segundo gráfico - um plano não euclidiano que descreve uma superfície sinusoidal; logo depois surge a palavra "Poem" e, por fim, após breve pausa, revela-se a frase que dá título à criação: Nous n'avons pas compris Descartes.

A articulação entre elementos de natureza semiótica tão díspar para a composição de sentidos no ciberpoema é condicionada pelo intertexto invocado pela frase francesa, transcrita de uma nota em que Mallarmé evoca o pensamento cartesiano, tão influente nas Humanidades em França:

Todo método é uma ficção e bom para a demonstração. A linguagem veio a ser o instrumento da ficção: segue-se o método da linguagem (determiná-lo). A linguagem se refletindo. Enfim, a ficção parece mesmo o processo do espírito humano - é ela que coloca em jogo todo método, e o homem é reduzido à vontade. Nós não compreendemos Descartes, os estrangeiros agarraram-no, mas ele catalisou os matemáticos franceses (Mallarmé, 1945, p. 851-856, tradução nossa).

\footnotetext{
${ }^{2}$ A despeito da aparente disparidade entre as linguagens verbal e matemática, cumpre ressaltar que o entendimento algébrico dos fenômenos linguísticos (e, por extensão, dos literários) marca uma significativa escola de pensamento nas ciências humanas - o Estruturalismo. Talvez um dos maiores pensadores de modelagens matemáticas para fenômenos verbais tenha sido o dinamarquês Hjelmslev, que baseou todo o seu sistema de pensamento acerca da linguagem no primado do significante sobre o significado. Chamando de Glossemática tal sistema, o programa de Hjelmslev trata "[...] a Linguística [como] uma espécie de álgebra, dentro da qual contam, para a definição da estrutura, as relações formais entre os elementos e não a materialidade dos elementos relacionados" (Hjelmslev, 2009, p. 8).
} 
Na nota de Mallarmé, a frase em questão postula uma crítica à forma como os franceses entendiam Descartes e seu célebre Discurso sobre o método, supostamente tomando-o apenas como um racionalista ortodoxo, em vez de reconhecerem que o método é uma ficção e, portanto, um processo autorreflexivo da linguagem. Reler Descartes e aproximar-se de seu sistema de pensamento sob uma perspectiva mais ficcional e metalinguística seria necessário, segundo Mallarmé, o que justifica suas especulações metapoéticas acerca dos limites e das potências da linguagem.

Tal perspectiva se replica na criação de André Vallias e condiciona mesmo nossa leitura da obra, na medida em que a primeira imagem que aparece na tela é uma superfície euclidiana meticulosamente quadriculada, a qual alude ao sistema de coordenadas em um plano cartesiano e, obviamente, amplifica as referências intertextuais ao racionalista francês.

Justaposta ao vocábulo "Page", a imagem pode ser lida tanto de forma icônica quanto simbólica. No primeiro caso, o plano representaria visualmente o formato de uma página, com comprimento e largura significativos, mas espessura/altura adimensional; no segundo caso, a uniformidade da superfície quadriculada conotaria as restrições impostas pela escrita linear, inerente ao sistema alfabético e reforçada pela platitude da linguagem cotidiana.

Em contraposição a essa imagem da página como espaço de uniformidade, o segundo gráfico de Nous n'avons pas compris Descartes, ao revelar uma sinuosa forma geométrica e associá-la à palavra "Poem", evidencia como a escrita poética desafia as convenções linguísticas e opera torções inesperadas na materialidade discursiva. Com dois centros de curvatura projetando-se para fora do plano original, a imagem afirma, por expedientes metapoéticos não verbais, a potência da poesia que extravasa os limites impostos pelo suporte (a página), pelo código (a língua), pelo referente (o mundo).

Se levarmos ainda em consideração que o autor da frase que dá título ao ciberpoema é Mallarmé - o mesmo que revolucionou, antes das vanguardas, o uso criativo do espaço da página na disposição visual dos signos -, a relação dialética entre a primeira e a segunda imagem se intensifica. Além disso, dado que o projeto estético mallarmaico tem como uma de suas premissas basilares a tensão entre acaso e regra na estruturação do poema, como na máxima "Um lance de dados jamais abolirá o acaso" (Mallarmé, 1945, p. 330, tradução nossa), a representação de uma superfície sinusoidal (e não de qualquer outra forma geométrica) na segunda imagem se revela prenhe de sentidos. Se gráficos como este tradicionalmente representam fenômenos probabilísticos e estatísticos, o conceito de poema postulado em Nous n'avons pas compris Descartes é o de fenômeno linguístico não trivial, advindo do improvável encontro de variáveis que, aleatoriamente, se encontram para transgredir os limites da página.

Ao valer-se de recursos geométricos para expressar asserções sobre a ars poetica, Vallias ressalta que seus gráficos são verdadeiros diagramas. Questionado sobre o conceito por trás de seus procedimentos de composição, o autor asseverou, em entrevista, que, para ele, tratava-se de um

"diagrama aberto": a leitura surge da inter-relação de variados códigos. Aliás, considero um "diagrama aberto" todo poema digno desse nome, quer faça uso explícito de elementos áudio-, numérico-visuais ou não. Acho o termo "linguagem verbal" extremamente simplificador (Vallias, 2015, s.p.).

Nesse contexto, o termo "diagrama", além de designar uma "estrutura gráfica representacional, caracterizada pelo estabelecimento de relações entre seus elementos" (Wiese, 2013, p. 151), é reinvestido dos significados etimológicos do prefixo grego diá (através) e da raiz grega graphein (escrever), a meio do caminho entre o poema e o gráfico matemático como formas de escrita através das quais sentidos são construídos.

Também no ciberpoema De verso, Vallias joga com elementos não verbais para construir diagramas que ensejam reflexões visuais sobre poética. No entanto, se em Nous n'avons pas compris Descartes o objeto da proposição metapoética é sua relação com o suporte da página, De verso se constitui de assertivas análogas às de um tratado de versificação.

Em uma seção introdutória ao ciberpoema, acessível apenas por meio do botão "intro", Vallias apresenta uma sequência de telas que se desenrolam em ritmo constante diante dos 
olhos do leitor. Nestas, cintilam elementos verbais e não verbais (estes, na forma de linhas retas e curvas) que progressivamente aludem a uma possível relação etimológica entre verso e versus, assim já descrita por Cohen (1974, p. 47): “Todo verso é versus, ou seja, retorno. Por oposição à prosa ('prosus'), que avança linearmente, o verso volta sempre sobre si mesmo". Na introdução a De verso, a alusão a tal étimo vai se construindo, tela a tela, na frase "uma linha estendendo-se em duas dimensões q pouco a pouco a pouco se aproximam por dentro e por fora", acompanhada pelo traçado de uma linha reta que vai se tornando curva e, por fim, espiralada, à medida que as telas avançam.

A seu turno, outra hipótese para a origem da palavra "verso" é trabalhada de forma metapoética na primeira ${ }^{3}$ tela de De verso: o uso de versus, em latim, para designar o sulco aberto por um arado (Vallias, 2007) posteriormente transposto por vias metafóricas para designar a organização em linhas de um poema. Lê-se nessa tela um breve terceto - "verso versus / volver / arar" - e, na sequência, quatro outras telas que apresentam uma mesma estrutura: a repetição do sintagma "o sulco" e uma alusão a um dos quatro principais pés métricos da tradição lírica ocidental - o troqueu, o iambo, o anapesto e o dáctilo. Para cada um deles, são apresentados, junto com seu nome: i) sua organização em sílabas fortes e fracas, representadas, como de costume em manuais de esticologia, por um traço horizontal e um semicírculo, respectivamente; e ii) o sentido contido na raiz grega de seu nome ("correr", "lançar", "rebater" e "dedo", respectivamente). Para fins de clareza, reproduz-se a seguir uma dessas telas, cuja transição na obra se dá automaticamente diante dos olhos do leitor (Figura 2).

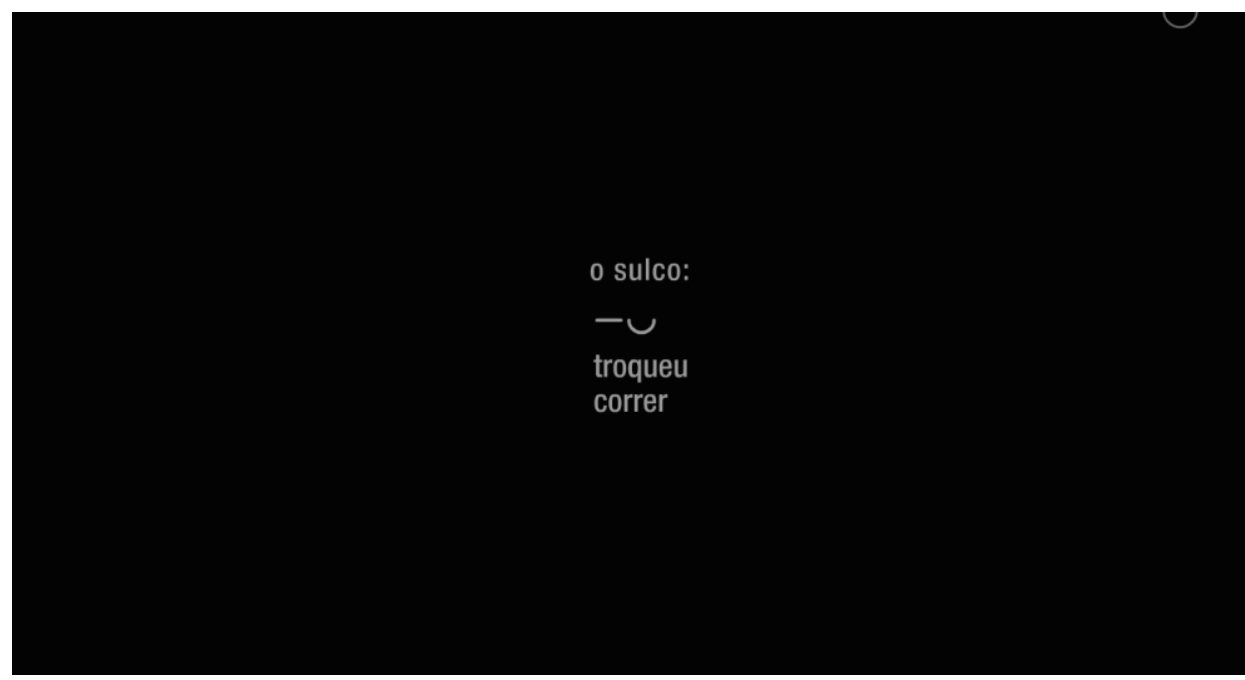

Figura 2 - Captura de tela da introdução de De verso

Fonte: Vallias (2003).

É interessante notar que a tradicional representação do padrão acentual do pé métrico, por meio de linhas retas e curvas, ganha motivação icônica na organização visual dos significantes nessa tela. Além da arbitrária associação entre essas linhas e a alternância entre sílabas fortes e fracas, o desenho composto por tais formas geométricas passa a sugerir o traçado dos sulcos abertos na terra pelo arado, reforçando o vínculo etimológico entre as ações de versejar e lavrar o solo.

Essa leitura se revela ainda mais pertinente quando, após assistir à passagem entre as quatro telas que apresentam os pés trocaico, iâmbico, anapéstico e dactílico, o leitor é redirecionado para uma outra em que, inicialmente, há apenas um plano quadriculado horizontal, bastante semelhante à primeira imagem constante em Nous n'avons pas compris Descartes (Figura 3).

\footnotetext{
${ }^{3}$ Trata-se da primeira tela caso o leitor, em vez clicar no botão "intro", opte por clicar em "pular".
} 


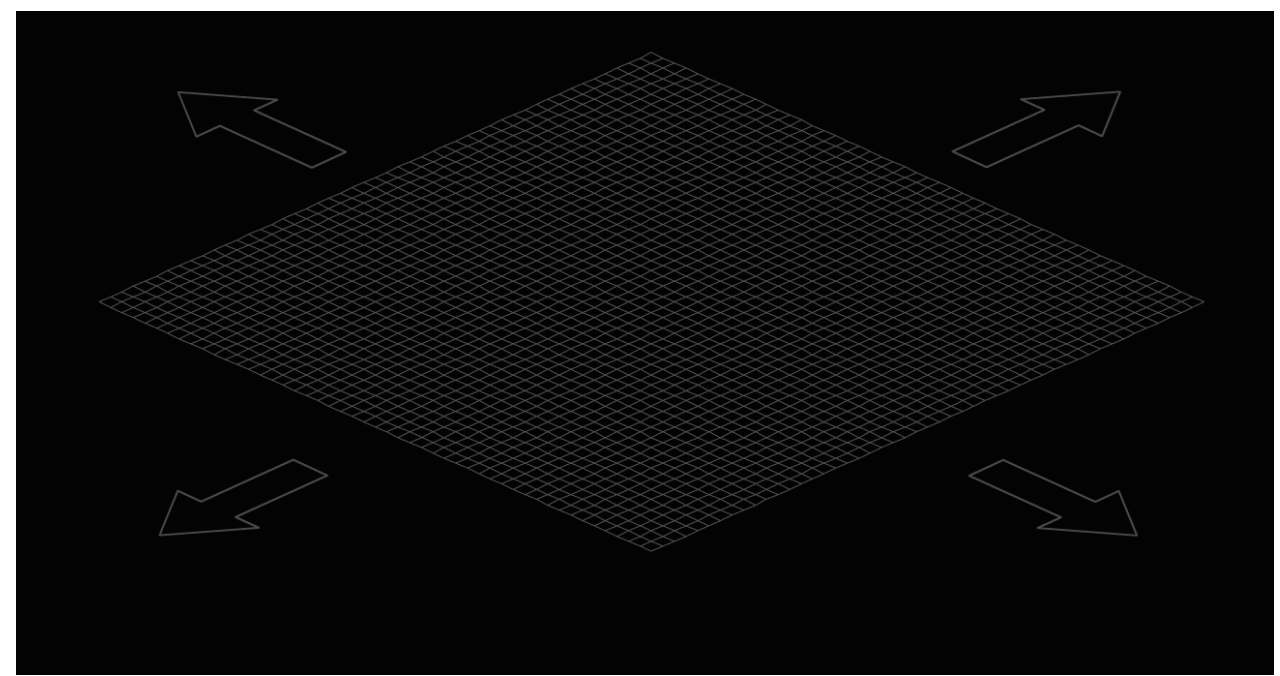

Figura 3 - Captura de tela de De verso

Fonte: Vallias (2003).

No entanto, diferente da obra anteriormente analisada, esta tem uma componente interativa - aspecto crucial para seus efeitos estéticos e caro a uma vasta gama de textos de poesia eletrônica -, entendendo-se aqui interatividade como a propriedade que permite que uma mídia seja alterada, em termos de forma ou conteúdo, por seus destinatários (Jensen, 1999). Assim, se em Nous n'avons pas compris Descartes o gráfico 3D que conduz à reflexão metapoética é de antemão dado a ver na interface, em De verso cabe ao leitor a construção do diagrama em eixos ortogonais, por meio da interação com os quatro botões em formato de seta.

Ao clicar em alguma das setas que circundam o plano quadriculado, o leitor desencadeia efeitos visuais nessa superfície, a qual se torna sulcada com reentrâncias retas e curvas, repetindo os padrões geométricos entrevistos na descrição esquemática dos pés métricos apresentados nas telas anteriores.

Conforme observado nas Figuras 4A e 4B, além de escolher um dos pés métricos para ser reproduzido imageticamente em indentações na superfície que até então era plana, pode o leitor combinar os efeitos visuais de diferentes pés, culminando na composição de até quinze gráficos tridimensionais. Pela manipulação experimental dos botões na interface, o usuário é como que convidado a deformar o plano quadriculado - metáfora da página consoante visto em Nous $n^{\prime}$ avons pas compris Descartes.

\section{$4 \mathrm{~A}$}

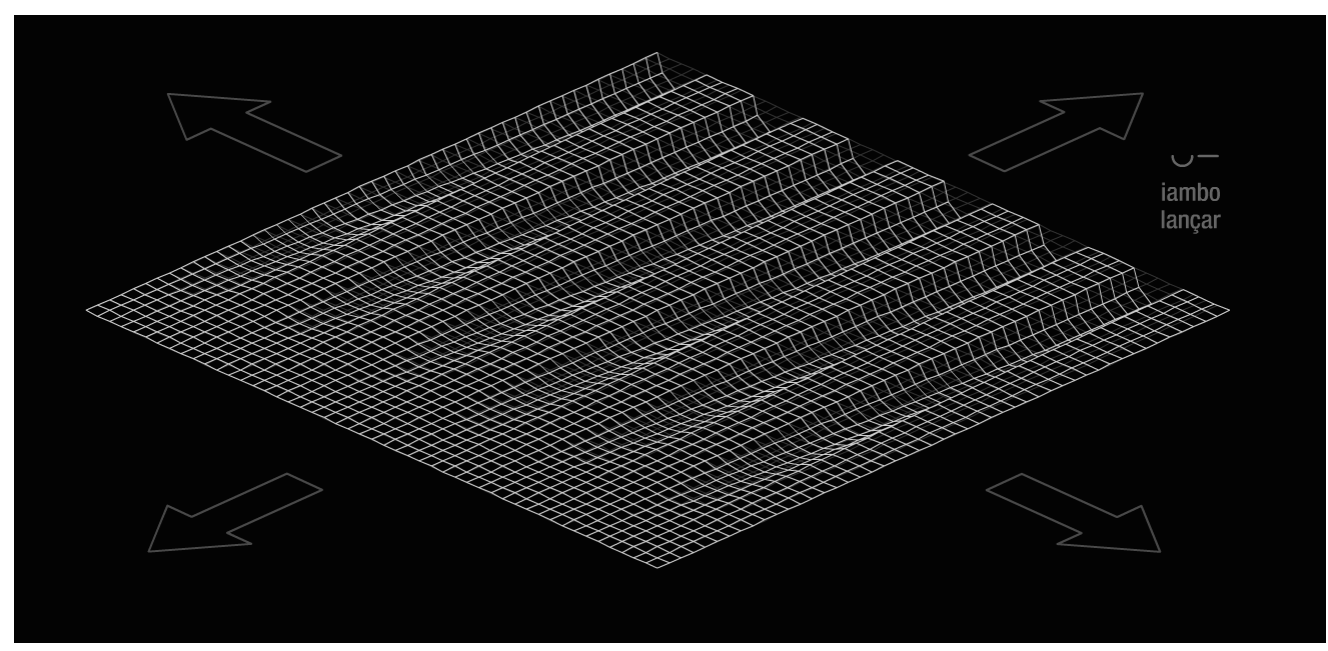


4B

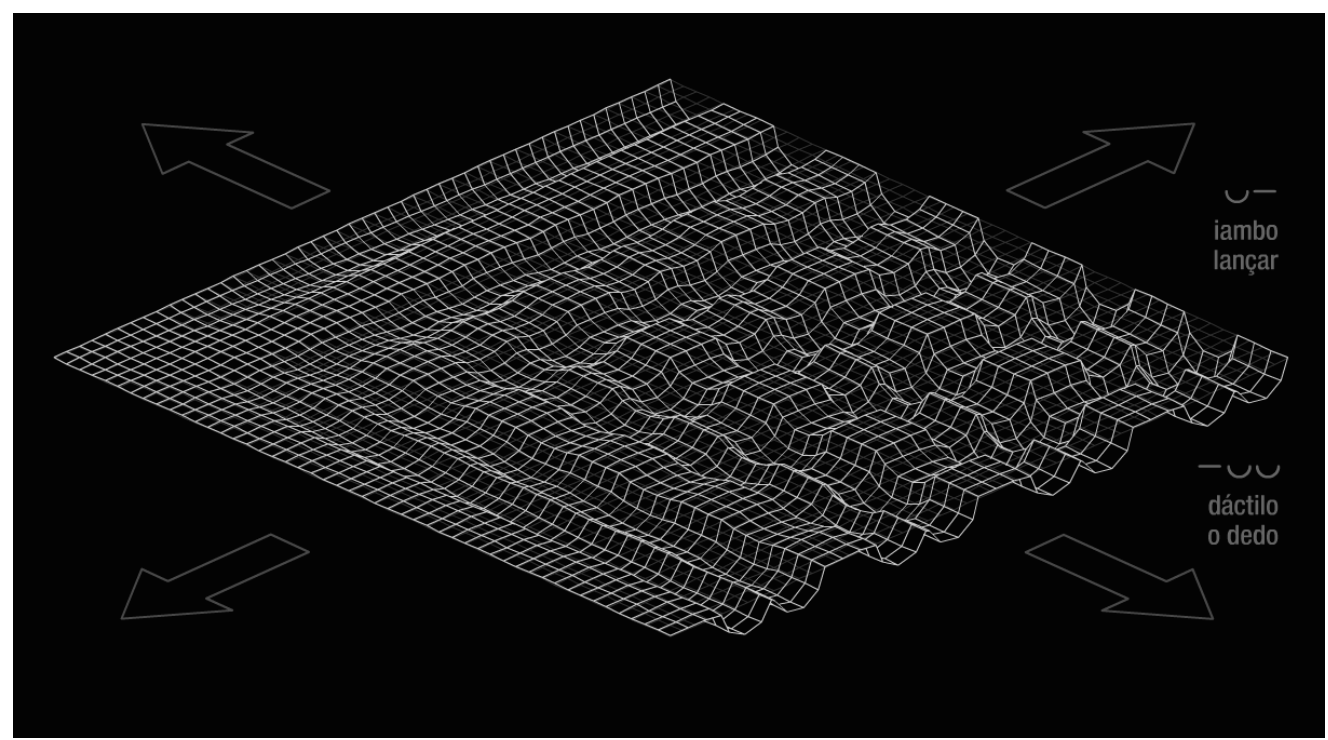

Figuras 4A e 4B - Capturas de tela de De verso após interação do leitor com os botões da obra

Fonte: Vallias (2003).

Conforme observado nas Figuras 4A e 4B, além de escolher um dos pés métricos para ser reproduzido imageticamente em indentações na superfície que até então era plana, pode o leitor combinar os efeitos visuais de diferentes pés, culminando na composição de até quinze gráficos tridimensionais. Pela manipulação experimental dos botões na interface, o usuário é como que convidado a deformar o plano quadriculado - metáfora da página consoante visto em Nous n'avons pas compris Descartes.

Se na obra analisada anteriormente neste artigo era clara a mensagem de que o poema é uma força subversiva a deformar a linguagem e mesmo o suporte, tal ideia se amplifica em De verso, na medida em que o leitor se torna corresponsável pelas mudanças impingidas à superfície que metaforiza a página. Nesse caso, embora não leia ou escreva versos, o leitor é convidado a experimentá-los por meio de impressões ópticas e hápticas, clicando no mouse para deformar o plano quadriculado segundo padrões do troqueu, iambo, anapesto ou dáctilo. Diante da inusitada possibilidade de experimentação com padrões rítmicos sem recurso a elementos verbais nessa obra, Funkhouser (2007) refere-se a ela como sendo do gênero code poem, isto é, um poema em linguagem não natural humana, emulando o funcionando dos códigos artificiais com que se programam máquinas.

Cumpre também ressaltar que a tangibilidade do ritmo convertido em gráfico 3D por uma ação mecânica da mão do usuário, clicando nos botões em forma de seta, empresta, por conseguinte, ares de performance ${ }^{4}$ ao ato de leitura de De verso, mobilizando a agência do corpo para, de uma interação, fazer emergir o fenômeno poético. E, em se tratando de performance, há também aqui uma componente de ficção e interpretação de papéis: o leitor faz de conta que é agricultor, manejando o arado que grava sulcos - poéticos, rítmicos, geométricos - na superfície por onde passa. Nesse processo, ao manipular uma metáfora visual que aproxima poema e solo, e não um conjunto de letras e palavras formando versos, o leitor tem uma experiência poética que é topográfica, e não tipográfica, apreendendo esquemas rítmicos com o olho na tela e a mão no mouse.

Acerca de tal apreensão sinestésica do ritmo poético, transpondo o audível para o visível e o tangível por meio de gráficos 3D, é iluminadora a reflexão de E. M. de Melo e Castro, que investiga

\footnotetext{
${ }^{4}$ Sobre a íntima relação entre interatividade e performance no uso de mídias digitais, conferir Saltz (1997) e sua análise de componentes performáticos da interação no ciberespaço, como a imprevisibilidade, a reiterabilidade, o predomínio da oralidade, o engajamento do corpo e da percepção etc.
} 
os possíveis significados que as tecnologias informáticas de simulação trazem à questão da representação 3D, apontando no sentido de uma tridimensionalidade virtual e desmaterializada, em que todas as possibilidades geométricas e simbólicas se potencializam. Tanto a anamorfose dinâmica, como a interatividade, podem ser estruturalmente sintetizadas nas imagens simuladas que, sendo constituídas por energia luminosa, atingem a qualidade da sinestesia que desde sempre esteve embutida em todos os níveis da representação tridimensional (Castro, 2014, p. 97).

A "anamorfose dinâmica" e interativa, a que se refere o poeta português, resta patente em $D e$ verso e nas transformações que o leitor pode realizar na representação tridimensional da superfície alterada pelos pés trocaico, iâmbico, anapéstico e dactílico. Tal uso de gráficos tridimensionais para representação do ritmo de versos é, a seu turno, revisitado e enriquecido por outros sentidos na obra Oratorio, em que o caráter dinâmico e fluido de "uma tridimensionalidade virtual e desmaterializada" (Castro, 2014, p. 97), composta de imagens luminosas na tela do computador, põe em diálogo gráficos 3D e a matéria verbal do ciberpoema.

Oratorio é uma obra em que Vallias desconstrói o gênero discursivo da oração religiosa, transpondo-o do espaço bíblico sacro para o eletrônico profano. Nessa criação, o autor faz do Rio de Janeiro o objeto de sua prece, como sugerido desde o título, decomponível na locução "Ora to Rio", e desde sua tela inicial, repleta de referências verbais e imagéticas à Cidade Maravilhosa, conforme se pode observar na Figura 5.

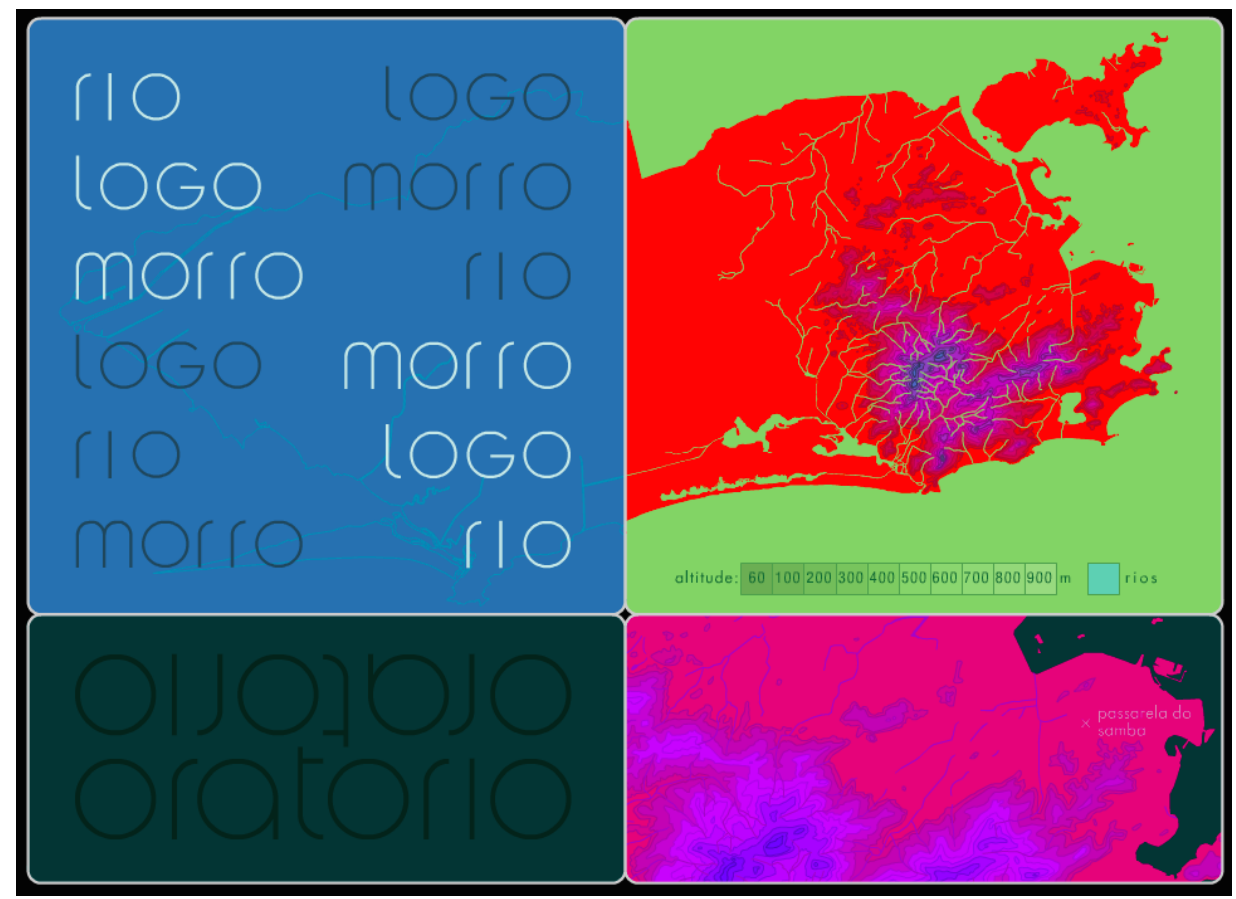

Figura 5 - Captura da tela principal de Oratorio

Fonte: Vallias (2004).

Agraciada com o Prêmio Bolsa-Estímulo IV Prêmio Cultural Sérgio Motta por suas virtudes estéticas e técnicas, Oratorio está entre as produções mais ricas de André Vallias, combinando elementos dos principais gêneros da literatura digital identificados por Torres e Barbosa (2000):

- A Poesia Animada por Computador, que, na continuidade da poesia visual, introduz a temporalidade na textura frequentemente multimediática da escrita em movimento no ecrã;

- A Literatura Generativa, que mediante "geradores automáticos" apresenta ao leitor um campo de leitura virtual constituído por infinitas variantes em torno de um modelo; 
- $\quad$ A Hiperficção ou narrativa desenvolvida segundo uma estrutura em labirinto, assente na noção de hipertexto, ou texto a três dimensões no hiperespaço, em que a intervenção do leitor vai determinar um percurso de leitura único que não esgota a totalidade dos percursos possíveis no campo de leitura (Torres e Barbosa, 2000, p. 2).

Os quatro retângulos coloridos na Figura 5 são botões que encaminham o leitor para diferentes segmentos da obra, nos quais abundam elementos multimídia para referenciar variadas facetas da cidade do Rio de Janeiro e entre os quais se estabelecem várias ligações em rede, formando uma complexa arquitetura hipertextual. Torna-se significativa essa estrutura reticular se pensarmos na também complexa teia de relações estabelecidas entre as diferentes partes da capital carioca, urbe caótica, interconectada por vielas, ruas, avenidas, estradas, túneis, pontes e o que o valha.

Entre os diversos percursos de leitura que a obra permite, dois merecem destaque para a discussão ensejada neste artigo, que tem como cerne o uso de gráficos 3D por Vallias para expedientes metapoéticos em suas criações. O primeiro percurso, ensejado pela imagem no retângulo superior direito da Figura 5, funciona como um mapa topográfico da cidade, no qual cores berrantes, num gradiente do vermelho ao roxo, mostram cortes do relevo carioca com diferentes altitudes. Nesse mapa, organizado como gráfico em curvas de nível, pode o leitor, clicando em variados pontos da escala, fazer sumir ou aparecer a distinção entre diferentes graus de elevação do terreno, ocultando ou explicitando a diversidade geográfica da cidade.

Tal funcionalidade interativa pareceria fortuita ou mesmo leviana, não fosse por um dado definidor da ocupação do espaço urbano carioca. Afinal, no Rio de Janeiro, a distinção entre encosta do morro ou planície litorânea não se resume a questões geológicas; trata-se, por uma série de conjunturas históricas e políticas, de uma divisão mais pronunciada e crucial para a vida dos moradores da capital fluminense, descrita pelo binômio favela x asfalto, síntese de um abismo social - aqui retomando intencionalmente a metáfora geográfica.

Desse modo, o recurso ao gráfico que expressa valores tridimensionais referenciais comprimento, largura e altura de variados pontos do relevo - para constituir um mapa da cidade se reveste em Oratorio de uma dimensão simbólica social, sublinhada pelos nomes das três localidades a que se tem acesso por meio do botão no retângulo inferior direito da Figura 5. Ao clicar nesse botão, o leitor é direcionado para uma versão ampliada do mapa do Rio de Janeiro em curvas de nível, mas agora pontuado pelos nomes de três localidades de diferentes altitudes e representações no imaginário carioca: a Favela da Rocinha, o Corcovado e a Passarela do Samba. Cada um desses nomes funciona também como botão na obra, remetendo o leitor a novas telas, em que se podem ler diferentes poemas sobre cada um desses lugares.

Por exemplo, caso o leitor clique no mapa sobre o nome "Favela da Rocinha", acede a uma outra seção da obra (Figura 6), na qual se observa uma tela com dois textos principais: na coluna à esquerda, um poema de vinte e um versos bem curtos (cada um composto por não mais que uma ou duas palavras); na da direita, mais um gráfico 3D de coordenadas ortogonais.

Os brevíssimos versos na coluna da esquerda descrevem a geografia recortada dos morros do Rio de Janeiro ("o dorso / inerme / da montanha"), os quais integram tanto os principais cartões postais da cidade quanto espaços urbanos periféricos, como a Favela da Rocinha, título da seção de Oratorio ora analisada. Como produto da ação antrópica, a favela, a seu turno, constitui também uma paisagem cheia de altos e baixos, em sua miríade de construções habitacionais distribuídas sem planejamento urbano estatal, de modo a formar uma "[trama / sobrescrita / em cursiva / alvenaria / (não-euclidiana)] / sela / cravejada / de tijolos / e concreto / armado / até os dentes:". A disposição visual dos versos, em que a verticalidade prepondera frente à horizontalidade na conexão entre as palavras, reforça a precariedade das casas que se superpõem na encosta do morro sem bases mais sólidas, suscetíveis que são às ações da erosão que "dilacera / o dorso / inerme / da montanha". 
Metaforizada como uma escritura irregular, de geometria improvável (e, portanto, "nãoeuclidiana"), a favela, como "cidadela / teia", é um conjunto de conexões (hipertextuais?) por vielas e becos, "armado /até / os dentes:". Note-se ainda que tal imagem é formada pela desconstrução da lexia concreto armado, a qual denomina usualmente um tipo de estrutura arquitetural, mas no poema ganha novos sentidos e conotações sociopolíticas por meio da hibridização com a expressão armado até os dentes.

Dialogando com tal representação verbal da Favela da Rocinha, a coluna à direita na tela apresenta um gráfico 3D de uma função algébrica, construído no software AutoCad, tal como nas imagens presentes em Nous n'avons pas compris Descartes e De verso. Em Oratorio, porém, o recurso ao gráfico matemático visa a outros efeitos estéticos, uma vez que se constitui como auxiliar na representação lírica da favela que se estende entre os bairros de São Conrado e da Gávea.

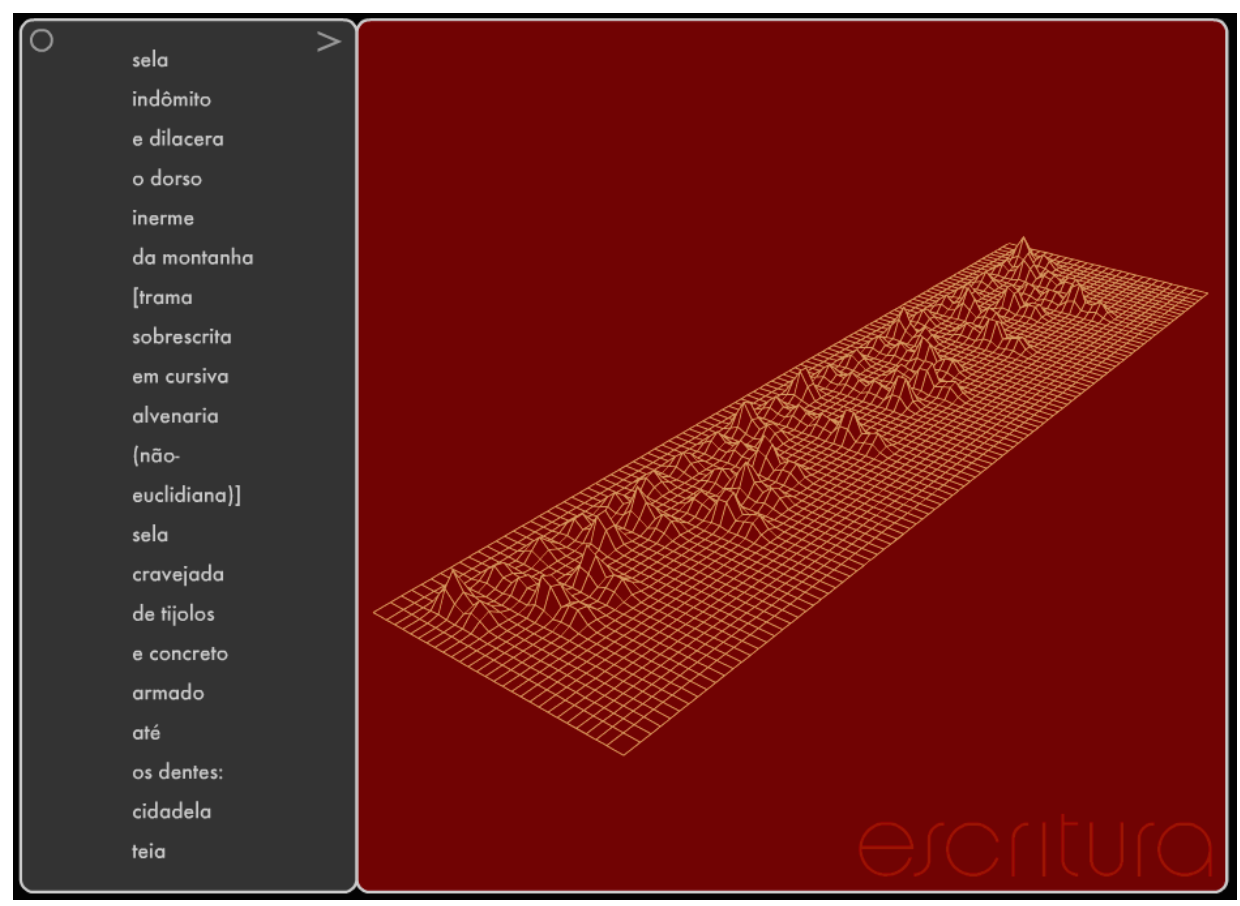

Figura 6 - Captura da tela inicial do poema "Favela da Rocinha", em Oratorio

Fonte: Vallias (2004).

Em primeiro lugar, não se pode deixar de perceber no diálogo entre a palavra, na coluna à esquerda, e o diagrama, na coluna à direita, que as diferentes alturas dos pontos no gráfico 3D indicam a pauta acentual de cada verso. Assim, a cada um dos vinte e um versos do poema corresponde uma forma geométrica organizada sobre as linhas horizontais no gráfico, cujos pontos mais altos indicam sílabas tônicas; pontos de altitude baixa, sílabas fracas; e pontos de altitude zero, o intervalo entre palavras. À guisa de exe mplo, observemse os primeiros dois versos do poema, formados pelos termos "sela" e "indômita". Se "sela" tem duas sílabas e a primeira é tônica, e "indômita" tem quatro sílabas e a segunda é tônica, correspondem a esses versos as formas desenhadas sobre as duas primeiras linhas do gráfico. A primeira forma, equivalente a "sela", tem dois pontos de virada projetados para "fora" do plano (sendo o primeiro deles "mais alto"); já a segunda forma, equivalente a "indômita", tem quatro pontos de virada projetados para "fora" do plano (sendo o segundo deles "mais alto").

Por meio de tal procedimento, Vallias transforma um fenômeno fonológico - a pauta acentual - em visual - a representação no gráfico matemático. Tal transposição semiótica, de cunho eminentemente metapoético, desafia nossa percepção de ritmo e nossas convenções acerca do lírico. O uso de gráficos tridimensionais para tal fim, também transgredindo os 
entendimentos mais assentes sobre o poético, pode ser ainda aproximado às reflexões que E. M. de Melo e Castro, poeta experimental português, desenvolveu acerca do que ele chamava de "transpoética 3D":

A representação de três dimensões numa superfície de apenas duas dimensões é uma questão transpoética porque transgride as próprias características dos suportes utilizados e dos objetos representados. Suportes: páginas de papel, quadro, tapeçaria, tela do cinema, tela do vídeo ou do computador. Objetos: todos os que existem na natureza, assim como os inventados pelo Homem. [...] Transpoética: poética que transgride os seus próprios limites (Castro, 2014, p. 95).

Como se nota no excerto, Melo e Castro associava o uso de imagens tridimensionais a procedimentos transpoéticos, isto é, que transgredissem limites do suporte ou do objeto representado. Como visto anteriormente, na análise de Nous n'avons pas compris Descartes, Vallias se valeu de um gráfico tridimensional (ainda que representado em uma superfície bidimensional, a tela do computador) para discutir a transgressão do suporte impresso para o digital; por sua vez, em De verso e Oratorio, o limite que se rompe pelos gráficos 3D é de ordem fenomenológica, de modo que fenômenos do estrato fonológico passam a ser representados por imagens que apelam aos olhos, e não aos ouvidos. No caso de De verso, o jogo se dá com a representação da alternância de sílabas longas e breves no âmbito de quatro tipos de pés métricos, que constituem a cadência poética em línguas de ritmo acentual; já em Oratorio, tratase de ilustração da alternância entre sílabas tônicas e átonas em uma língua de ritmo silábico, como o Português do Brasil (Cagliari, 2012).

Também como em De verso, os gráficos matemáticos de Oratorio podem ser lidos de modos outros que não só os simbólicos, isto é, como diagramas de ritmo poético. Em ambas as obras, as linhas de representação algébrica também podem ser compreendidas por uma perspectiva icônica: assim, se em De verso os gráficos desenhavam os sulcos abertos pelo arado, em Oratorio eles dão a ver as cadeias de morros, picos e vales que constituem a acidentada paisagem carioca, coalhada de pequenos casebres superpostos e justapostos em irregulares encostas.

Superposição e justaposição são termos de importância fulcral para essa poética topográfica - lendo-se topos como espaço tanto geográfico quanto retórico. Afinal, tais quais as construções arquitetônicas na favela, que vão se fazendo uma colada à outra, uma em cima da outra, também de blocos enfileirados ou empilhados se constrói o poema verbal na coluna à esquerda da tela. Navegando por pequenos botões em formato de seta, dispostos no alto dessa coluna, o leitor acede a outras telas semelhantes às da figura 6, nas quais continuam se desenrolando os versos sobre a Favela da Rocinha; à direita, atualiza-se sua representação em gráficos 3D conforme a pauta acentual dos novos versos que, durante a navegação, aparecem na coluna à esquerda.

Os versos nessas outras telas mantêm a brevidade formal dos anteriores e aprofundam a imagem que relaciona a geografia acidentada da cidade e os contornos dos apinhados casebres a uma escritura irregular e poligonal, análoga à formada pelos gráficos em 3D na obra. Em uma das sucessivas telas, lê-se que o horizonte se divisa como uma "aorta / única / do labirinto / [caos / compartido] / fluindo / sem guarda / e sem grito / nas curvas / inflexas / do ex- / trampolim / do diabo", em que as formas geométricas, como "curvas / inflexas", desenham uma escritura de justaposições e superposições de picos, morros e vales. Tal interpretação torna-se ainda mais plausível quando notamos que, na última tela do poema sobre a Favela da Rocinha a que pode chegar o leitor, não há mais uma estrofe justaposta às demais, e sim uma superposição de todas as estrofes anteriores, como se vê na Figura 7. Forma-se, pois, um palimpsesto ilegível a metaforizar o caos urbano da cidade, bem como a cacofonia dos sons da favela ou dos ritmos do poema, caso experienciados simultaneamente. 


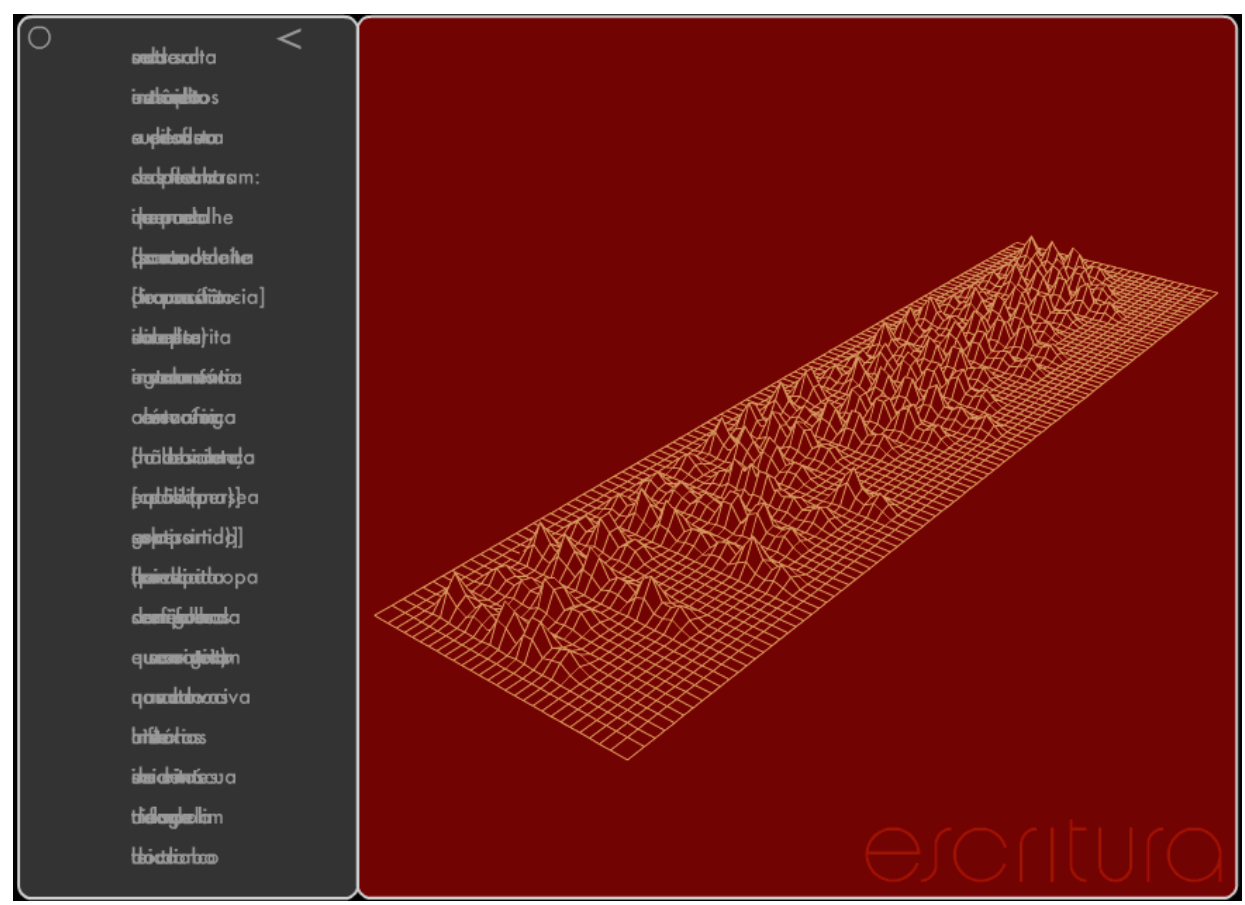

Figura 7 - Captura da última tela do poema "Favela da Rocinha", em Oratorio

Fonte: Vallias (2004).

Para além da ilegibilidade dos versos escritos uns por cima dos outros - conglomerado visual de complexidade semiótica algo análoga à espontaneidade com que a favela se desenvolve, geralmente sem intervenção do poder público -, curioso é notar que, na coluna à direita, há também uma superposição dos gráficos. Há, nesse ponto, uma representação tridimensional do ritmo de todos os versos simultaneamente, o que culmina num gráfico de difícil leitura em termos de sua representação de fenômenos do estrato fonológico do poema, mas, ao mesmo tempo, compõe um ícone mais realista da acidentada topografia das cadeias de morros cariocas. Diante da algaravia das palavras superpostas na coluna à esquerda, só resta ao leitor, então, a apreciação da paisagem poética e geográfica à direita, fruindo um poema que desemboca em uma crise do verbo, seja para falar da cidade, seja para descrever o ritmo do próprio poema. Desenleados da palavra, os gráficos tridimensionais se tornam, então, acontecimentos poéticos em si, reforçando a tese, neste artigo defendida, de que os sistemas 3D de coordenadas ortogonais devêm material metapoético na obra de Vallias, em que o lírico se expressa por uma inaudita semiose matemática.

\section{Considerações finais}

Ao longo da história da escrita e suas variadas tecnologias, a relação entre imagem e palavra, isto é, entre o ver e o ler, foi se reconfigurando em diferentes movimentos dialéticos, ora liberando, ora disciplinando o traço riscado sobre uma superfície, seja este parte de um grafema, de um desenho, ou de algo a meio do caminho entre ambos. Em tempos de tecnologias digitais - estes em que André Vallias produziu as obras analisadas no presente artigo -, tanto a mobilidade dos signos quanto a qualidade técnica de sua representação cresceram exponencialmente, permitindo novas formas de experimentos poéticos em diálogos intersemióticos.

No caso mais específico dos poemas eletrônicos de Vallias, os trânsitos entre diferentes linguagens frequentemente envolvem o recurso a gráficos matemáticos $3 \mathrm{D}$, isto é, a funções algébricas que são visual e tridimensionalmente expressas em eixos cartesianos ortogonais, construídas no software AutoCad. Tais gráficos figuram de variados modos em sua obra, seja como poemas em si mesmos, seja como parte de textos híbridos, que combinam imagens 
verbais e algébricas em criações artísticas multimídia, tais como os três ciberpoemas analisados neste artigo: Nous n'avons pas compris Descartes (1997), De verso (2003) e Oratorio (2004).

Por meio de um close reading desse corpus, puderam-se identificar alguns tipos de efeitos estéticos decorrentes da inusitada presença dos gráficos 3D: a referencialidade que as coordenadas dos eixos tridimensionais podem assumir, lembrando montanhas, vales, sulcos, dobras e outras entidades do mundo real; a aproximação entre matemática e literatura, como esferas de manipulação sígnica de potencialidade artística; e a representação diagramática metapoética de elementos estruturantes da poesia, sobretudo os atinentes ao estrato fonológico.

Nas obras aqui analisadas, bem como em outras criações de Vallias, tais usos se sobrepõem, de modo que um único gráfico pode operar simultaneamente como ícone e símbolo, se recorrermos à terminologia peirceana. Trata-se, afinal, de uma topografia artística, em que topos matemáticos, geográficos e retóricos se imbricam em uma poética cartesiana - ou, pelo menos, que se estrutura a partir de gráficos, escritas e desenhos, enfim, no plano cartesiano.

\section{Referências}

ANDRÉ Vallias (Verbete) (2018). In: ENCICLOPÉDIA Itaú Cultural de arte e cultura brasileiras. São Paulo: Itaú Cultural. Disponível em: http://enciclopedia.itaucultural.org.br/pessoa101493/andre-vallias. Acesso em: 21 fev. 2019.

ANDRÉ Vallias (Verbete) (2019). In: ELECTRONIC literature as a model of creativity and innovation in practice - ELMCIP (2019). Disponível em: https://elmcip.net/node/4941. Acesso em: 20 fev. 2019.

ANTONIO, Jorge Luiz (Comp.) (s.d.) Brazilian digital art and poetry on the web. Disponível em: http://www.vispo.com/misc/BrazilianDigitalPoetry.htm. Acesso em: 20 fev. 2019.

CAGLIARI, Luiz Carlos (2012). Línguas de ritmo silábico. Revista de Estudos da Linguagem, Belo Horizonte, v. 20, n. 2, p. 23-58, jul./dez. Disponível em: https:/ /bit.ly/2ZPy5aD. Acesso em: 29 mar. 2019.

CASTRO, Ernesto Manuel de Melo (2014). Poética do ciborgue. Rio de Janeiro: Confraria do Vento.

COHEN, Jean (1974). Estrutura da linguagem poética. São Paulo: Cultrix.

FUNKHOUSER, Christopher Thompson (2007). Prehistoric digital poetry: an archaeology of forms, 19591995. Tuscaloosa: University of Alabama.

HAYLES, Katherine (2009). Literatura eletron̂ica: novos horizontes para o literário. São Paulo: Global.

HJELMSLEV, Louis (2009). Prolegômenos a uma teoria da linguagem. São Paulo: Perspectiva.

JENSEN, Jens F. (1999). 'Interactivity'. Tracking a new concept in media and communication studies. In: MEYER, Paul A. (ed.). Computer Media and Communication: a Reader. Oxford: Oxford University Press. p. 160-187.

MALLARMÉ, Stéphane (1945). Oeuvres complètes. Paris: Bibliothèque de la Pléiade.

OULIPO (1973). La littérature potentielle. Paris: Gallimard.

SALTZ, David Z. (1997). The art of interaction: interactivity, performativity and computers. Journal of Aesthetics and Art Criticism, Illinois, v. 55, n. 2, p. 117-127. Disponível em: https://www.jstor.org/stable/431258?seq=1. Acesso em: 22 fev. 2019.

SANTAELLA, Lúcia (2012). Para compreender a literatura digital. Texto Digital, Florianópolis, v. 8, n. 2, p. 229-240, jul/dez. Disponível em: https:/ / bit.ly/2FBZuTX. Acesso em: 20 fev. 2019.

SANTOS, Alckmar Luiz dos (2003). Leituras de nós. Ciberespaço e literatura. São Paulo: Itaú Cultural.

TORRES, José Manuel; BARBOSA, Pedro (2000). Sintext-Web: um gerador de texto automático como instrumento computacional de criação literária. Revista da Universidade Fernando Pessoa, Porto, v. 5, set. Disponível em: https:// bit.ly/2Fsz4UV. Acesso em: 20 fev. 2019.

VALLIAS, André (1997). Nous n'avons pas compris Descartes. Disponível em: http://www.andrevallias.com/poemas/nous.htm. Acesso em: 10 mar. 2019. 
VALLIAS, André (2003). De verso. Disponível em: http://www.andrevallias.com/deverso/deverso.htm. Acesso em: 20 fev. 2019.

VALLIAS, André (2004). Oratorio. Disponível em: http://www.andrevallias.com/oratorio/. Acesso em: 30 fev. 2019.

VALLIAS, André (2007). We have not understood Descartes. In: KAC, Eduardo. Media poetry: an international anthology. Bristol: Intellect Books.

VALLIAS, André (2015). ELR entrevista André Vallias. Eletronic Literatura Review, [s.1.], $1^{\circ}$ jul. Disponível em: https:// bit.ly/36kXGuo. Acesso em: 22 fev. 2019.

WIESE, Maíra Borges (2013). O poema como um diagrama aberto: a poesia gráfico-digital de André Vallias. Texto Digital, Florianópolis, v. 9, n. 1. Disponível em: https:// bit.ly/2tqSo1V. Acesso em: 20 fev. 2019. 